\section{VERTICALIZAÇÃo \\ E PERMEABILIZAÇÃO \\ DO SOLO URBANO NOS \\ SETORES CENSITÁRIOS DE BELO \\ HORIZONTE/MG ${ }^{1}$}

\author{
VERTICALIZATION AND SOIL SEALING \\ IN THE CENSUS TRACTS OF BELO HORIZONTE/MG
}

\author{
Carlos Lobo \\ Universidade Federal de Minas Gerais, Instituto de Geociências, \\ Programa de Pós-Graduação em Geografia, Belo Horizonte, MG, Brasil \\ Diego Ferreira Fonseca \\ Prefeitura Municipal de Belo Horizonte, Belo Horizonte, MG, Brasil \\ Ricardo Alexandrino Garcia \\ Universidade Federal de Minas Gerais, Instituto de Geociências, \\ Programa de Pós-Graduação em Geografia, Belo Horizonte, MG, Brasil
}

\begin{abstract}
1 Agradecimento à Fundação de Amparo à Pesquisa do Estado de Minas Gerais (FAPEMIG) pelo apoio financeiro concedido por meio do Programa "Pesquisador Mineiro".
\end{abstract}

R E S U M O : Nas últimas décadas, a discussão sobre a formaldensidade de ocupação e a qualidade ambiental do espaço urbano ganhou ampla repercussão no cenário político e na mídia internacional. Por sua vez, a relação especifica entre a verticalização construtiva e o nivel de impermeabilização do solo tem sido objeto de recorrentes debates e controvérsias na literatura acadêmica. Embora a influência positiva de áreas permeáveis na qualidade do ambiente urbano pareça consensual, sobretudo no que diz respeito às dinâmicas atmosférica e hídrica, tem-se a necessidade de produção de informaçóes mais precisas, detalhadas e úteis para a tomada de decisão na esfera política e no âmbito do planejamento territorial, especialmente naquele sob competência do poder público. A partir de técnicas de geoprocessamento e métodos de estatística inferencial e espacial, este artigo tem como objetivo avaliar a relaçáo entre a verticalização construtiva e o nivel de impermeabilização do solo urbano, tendo como unidade de análise os setores censitários do municipio de Belo Horizonte/MG em 2000. Considerando os resultados do modelo de regressão linear local, não foram observados niveis significativos de determinação da impermeabilização do solo, em função dos valores de altura das edificaçôes. Destaque-se, contudo, que os clusters identificados com alto nivel de verticalização corresponderam exatamente àqueles com maiores niveis de impermeabilizaçâo.

P A L A V R A S - C H A V E : verticalização; permeabilização do solo urbano; Belo Horizonte. 


\section{INTRODUÇÃO}

As maiores transformações da civilização moderna ocorreram nos últimos cem anos, sobretudo nas grandes cidades (FUNDAÇĀO JOÃO PINHEIRO, 1996). O crescimento urbano, que já experimentou certa tendência de estabilização nos países desenvolvidos, onde os efeitos da transição demográfica se manifestaram há tempos, deu sinais de arrefecimento nos países em desenvolvimento. Apesar disso, a expansão das áreas urbanas na atualidade parece impor sérios limites à melhoria da qualidade de vida nas grandes cidades, a exemplo dos gargalos de mobilidade e dos recorrentes problemas ambientais em áreas urbanas. Como assinala Zahn (1983), levantamentos da Organização das Nações Unidas (ONU) divulgados no final do século passado demonstraram que o contingente populacional urbano cresceu de 704 milhóes em 1950 (28\%) para 1.352 milhóes em 1970 (37\%), o que representou um incremento bruto de $92 \%$ (enquanto a população total cresceu apenas 46\%). Projeçôes da ONU publicadas em 2014 estimavam uma população urbana mundial de 3.329 milhōes (51\%) para o final do século XX. Em 2014, conforme novas estimativas da organização, $54 \%$ da população mundial vivia em áreas urbanas, proporção que, assim se espera, atingirá 66\% em 2050 (UNITED NATIONS, 2014).

O incremento técnico-acumulativo ocorrido no século passado intensificou o processo de exploração da natureza pelo homem, superando algumas das restriçóes naturais impostas pelo ambiente modificado. Após a Segunda Guerra Mundial, o aumento das forças produtivas, impulsionado pelo progresso científico e técnico, rompeu com todas as proporçôes históricas anteriores. O sistema produtivo, indo além da exploração de recursos naturais, passou a produzir uma "outra natureza", que, materializada nos grandes aglomerados urbanos, redimensionou as formas de ocupação e de transformação da superfície terrestre em seus diversos subsistemas. A cobertura vegetal, os recursos hídricos e os componentes atmosféricos foram sensivelmente afetados. A intensidade do adensamento humano nas cidades industriais teve forte efeito perturbador no clima local.

Avaliar os efeitos decorrentes da atividade humana é uma tarefa cada vez mais essencial da administração pública municipal, em particular nos âmbitos da gestão e do planejamento territorial, que devem ter o propósito de melhorar a qualidade de vida das populaçóes que vivem nas cidades. Nesse contexto, uma questáo que recorrentemente tem envolvido o debate político, sendo citada pela literatura técnico-científica, refere-se à perda de área permeável, resultante, como se supóe, do forte adensamento populacional e da chamada verticalizaçáo construtiva.

Este trabalho analisa a possível influência do processo de verticalização construtiva nos níveis de impermeabilização do solo urbano. A hipótese investigada, com base em técnicas de Geoprocessamento/Processamento Digital de Imagens e em métodos de Estatística Espacial e Inferencial, é a da suposta relação de determinação estatística (regressão linear) da variável de proporção de áreas impermeáveis pela altura média das edificaçóes, tendo como exemplo analítico os setores censitários do município de Belo Horizonte. Foram utilizadas as bases vetoriais que compóem o cadastro municipal das edificaçôes da Prefeitura Municipal, o levantamento plano/altimétrico e o mosaico de cenas, obtido pelo sistema sensor RapidEye, de todo o território do município de Belo Horizonte. 


\section{VERTICALIZAÇÃO E PERMEABILIZAÇÃO DO ESPAÇO URBANO: PROMESSAS E CONTROVÉRSIAS DA CHAMADA “CIDADE COMPACTA"}

Como destacam Santos e Tavares (2011), o espaço urbano apresenta-se como objeto intrínseco do processo de acumulação capitalista, o qual se transformou em mercadoria de alto valor, favorecendo a ampliação da mais-valia de grupos seletos inseridos no sistema financeiro mundial. Para Machado e Méndes (2003), a verticalização pode ser vista como uma materialização das transformações técnicas que atingem as cidades contemporâneas. Não deve ser considerada como uma consequência natural do processo de urbanização, mas sim como uma das possíveis opçóes traçadas e definidas pelos diferentes fatores sociais e pelos interesses econômicos que envolvem a estrutura das cidades. Ela é, ainda, uma das grandes responsáveis pelas alteraçóes morfológicas e funcionais de amplos segmentos da paisagem urbana, a qual permitiu a existência e multiplicação de solos superpostos e a revalorização do espaço pelo aumento do potencial de aproveitamento (MACEDO, 1987)2 .

Santos e Tavares (2011) pontuam que o processo de verticalizaçáo aparece como uma das principais modalidades de apropriaçáo do espaço urbano nas grandes cidades do mundo e também no Brasil, pois representa um tipo de habitação - ao menos no discurso racionalizante global - atrelado ao que há de moderno, o que gera no mercado habitacional expectativas e sentimentos de satisfação. Esse processo é tanto resultado da multiplicação do solo urbano (FERREIRA, 1987) quanto produto no espaço de uma estratégia entre múltiplas formas de capital: o fundiário, o imobiliário e o financeiro (SOUZA, 1989). Como resultado da multiplicação do solo urbano (SOUZA, 1994; SOMEKH, 1997), no Brasil, a verticalização também esteve associada, sobretudo, à habitação e não ao setor de serviços, como aconteceu em muitos outros países do mundo. Ademais, apesar de algumas experiências isoladas, ao analisar o caso da capital paulista, Somekh (1997) destaca que os apartamentos não eram opção de moradia barata da classe baixa, mas sim a opção para uma elite cultural inclinada aos padróes de modernidade ou para uma classe média formada por imigrantes (RAMIRES, 1998)3. Souza (1994, p. 138) afirma que "a produção de edifícios constitui[u]-se [como] uma possibilidade inusitada de articulação das múltiplas formas do capital num objeto - o edifício, num mesmo lugar - o urbano, num tempo/circulação extremamente reduzidos".

O processo de verticalização tem sido acompanhado por outras questôes não menos relevantes, como segregação social, revisão da legislação urbana e agravamento dos problemas ambientais (MENDES, 1992). Para Scussel e Sattler (2010), o exame da literatura permite afirmar que a verticalização não é, em si, boa ou má. A questão é bem mais complexa, estando relacionada a um conjunto de fatores, como custos de infraestrutura urbana, tipologia das edificações, estruturação da malha viária, que, combinados, definem a qualidade do espaço urbano.

A mudança na paisagem urbana é apenas um dos elementos decorrentes do processo de verticalizaçấo e está ligada ao comprometimento da relação homem-meio (MACHADO; MENDES, 2003), a qual produz reflexos diretos no meio físico, incluindo impactos ambientais no clima urbano, na drenagem, na cobertura vegetal,
2 É possível compartimentar o espaço urbano, segundo seus elementos físicos, em três sistemas integrados: sistema de espaços com construções, sistema de espaços de integração viária e sistema de espaços livres de construção (CAVALHEIRO; DEL PICCHIA, 1992). Como espaço livre, compreende-se qualquer espaço urbano fora das edificações e ao ar livre, de caráter aberto, e que, independentemente do uso, seja destinado ao pedestre e ao público em geral. Os espaços livres de construção, como elementos integradores da paisagem urbana, são normalmente associados à função de lazer, como praças, jardins ou parques, que devem ser elaborados de acordo com as atividades e necessidades do homem urbano, a fim de favorecer a qualidade de vida nas cidades.

3 Para Ramires (1998), apesar das controvérsias, é possível identificar alguns pontos de consenso nos debates sobre a verticalização e temas afins: 1ㅇ) eles entendem a verticalização como um fato típico dos tempos modernos, e, na maioria dos trabalhos, o arranha-céu é apontando como um marco revolucionário para a fisionomia das cidades; 2ㅇ) veem a verticalização como representante de uma revolução na forma de construir, evidenciando a importância da técnica na produção do espaço urbano; 3) apontam a verticalização como responsável por profundas alterações na estrutura interna das cidades, com destaque para as transformações sociais; 4의) eles reforçam a necessidade de ação do poder público para disciplinar o processo de verticalização por meio de zoneamentos, definição de gabaritos de prédios, estipulação das taxas de ocupação e de índices de aproveitamento (legislação urbana) 5ㅇ) sublinham a necessidade de incorporar a análise da lógica imobiliária na compreensão da produção do espaço urbano; 6ㅇ) destacam a necessidade de periodização como uma forma de contextualização histórica do processo de verticalização (análise por etapas). 
4 Normalmente, a cobertura vegetal tende a estabilizar os efeitos do clima local nos arredores imediatos, minimizando condições de extremos térmicos e hídricos. 0 próprio processo de fotossíntese, responsável pela reciclagem de oxigênio e gás carbônico, auxilia na umidificação atmosférica. Os benefícios gerais que as áreas verdes possuem não são poucos, e alguns são de grande relevância - por exemplo, as propriedades de permeabilidade e fertilidade do solo são mantidas em áreas que possuem vegetação.

5 Nas áreas arborizadas, parte da energia obtida é utilizada na evaporação da água superficial e infiltrada no solo e também na evapotranspiração, favorecendo um menor acúmulo de energia.

6 Numa escala global, como sugere Glaeser (2011), metade dos seres humanos ocupa $4 \%$ das terras cultiváveis, o que libera mais espaço para a agricultura e para as áreas verdes.

7 Nas últimas décadas, sobretudo após a Segunda Guerra Mundial, prevaleceu um modelo de urbanização fundamentado nos princípios da "Carta de Atenas" (CIAM, 1933), que, mais tarde, culminou no Congresso Internacional de Arquitetura Moderna. Um documento dela resultante, publicado por Le Corbusier em 1942, concentrava-se no conceito de "cidade funcional", baseado na criação de zonas independentes para as funções de habitação, trabalho, lazer e circulação (SILVA, 2008). Um bom exemplo de cidade fundado nesse paradigma é Brasília. De acordo com Silva (2008), esse modelo urbanístico é desarticulado, com componentes que não interagem ou que tornam os custos muito elevados. Com base nesses princípios de funcionalidade, o planejamento urbano das grandes cidades tem fomentado o desenvolvimento de estruturas amorfas, extremamente consumidoras de tempo e energia, nas quais as estradas determinam a geometria urbana, com edifícios ligados às rodovias e cada vez menos interligados. no conforto térmico e na qualidade do ar (NUCCI, 2001). Nesse aspecto, alguns dos graves problemas presentes nas grandes cidades do Brasil e do mundo são a escassez de áreas verdes e a excessiva impermeabilização do solo, cujas consequências são observadas no comportamento térmico das áreas urbanas e na agudização dos processos erosivos $^{4}$. A existência de áreas verdes ou permeáveis, entre outros aspectos, também interfere no equilíbrio térmico, alterando a quantidade de vapor de água na atmosfera e a absorção do calor ${ }^{5}$. Já a permeabilidade do solo é essencial ao controle natural das enchentes, tão frequentes nos principais centros urbanos do país. Conforme as condiçôes da superfície do solo, a água pode nele se infiltrar e seguir vários caminhos em seu interior até atingir, por vezes, as águas superficiais, de forma lenta e contínua. A água que permanece na superfície do solo escoa rapidamente em direção ao sistema de drenagem superficial, formado por canais artificiais, rios, lagos e reservatórios. Essa parcela da precipitação é a principal responsável pela formação das enchentes (PINHEIRO, 2007).

Apesar do relativo consenso sobre a importância da cobertura vegetal e da permeabilização do solo para o equilíbrio ambiental das cidades, constata-se, com certa frequência, que essas áreas verdes não têm sido devidamente protegidas da expansão territorial e do crescimento populacional das principais cidades brasileiras, sendo alvos recorrentes de agentes do mercado imobiliário. A expansão urbana não deve ser interpretada necessariamente como um problema, sobretudo nos casos em que ela é planejada e monitorada de modo adequado pelo poder público; existem, na literatura, estudos que indicam que aglomeração espacial pode ser positiva do ponto de vista ambiental ${ }^{6}$.

Segundo Silva (2008), as cidades atuais desenvolveram-se à custa das tecnologias de transporte que emergiram em fins do século XIX e princípios do século XX, quando, para o mesmo tempo de viagem, foram ampliadas, consideravelmente, as distâncias percorridas. Recursos passaram a ser consumidos em larga escala e, concomitantemente, geraram-se enormes montantes de desperdícios e de emissóes de gases de efeito estufa, entre outros poluentes.

As cidades contemporâneas, estruturadas sob a lógica do transporte rodoviário, centrado no automóvel individual e nos grandes edifícios monofuncionais, em detrimento do transporte coletivo de massa e dos espaços públicos, devem ser repensadas e rediscutidas, e o aparato tecnológico deve estar a serviço da sociedade na busca por cidades sustentáveis (LIMA, 2014) ${ }^{7}$. A urbanização espacialmente dispersa representaria, nesse cenário, o desenvolvimento das cidades em função do transporte motorizado e individual, pouco sustentável do ponto de vista ambiental. Além disso, haveria um consumo excessivo do solo, com a redução da presença de áreas permeáveis e o aumento do congestionamento de veículos, dos níveis de ruído, da poluição atmosférica, associado aos elevados custos em infraestruturas e à ineficiência do fornecimento de serviços pelas autoridades locais.

Rogers e Gumuchdjian (1997) propõem uma organização das cidades fundamentada em um conceito de cidade compacta, que exige a rejeição do modelo de desenvolvimento monofuncional e da predominância do automóvel, princípios iconográficos do pensamento moderno. O foco dessa lógica reside em uma concepção de planejamento que permite uma mobilidade urbana eficiente, uma menor emissão de $\mathrm{CO}_{2}$ e uma maior dinâmica entre espaços multifuncionais, espaços públicos e cidadãos (LIMA, 2014). O modelo de "cidade compacta" apresenta, portanto, um 
paradigma de desenvolvimento urbano que intenta responder a um conjunto de problemas associados ao modelo "extensivo" de cidade 8 . A lógica do discurso daqueles que defendem essa proposta baseia-se na ideia de que vias pavimentadas, redes de esgotos e linhas de transmissão elétrica menos extensas (isto é, mais próximas ao local de residência/trabalho/estudo), somadas à possibilidade de redução de deslocamentos por meio de carros e de aumento da quantidade de pessoas que frequentam o mesmo lugar, favoreceriam a melhora da qualidade de vida da população e diminuiriam o impacto negativo sobre o ambiente urbano9. Para Acselrad (1999), o discurso da sustentabilidade urbana foi pretensamente apresentado como uma promessa de articular, centrado na intervenção da forma urbana como fator determinante, as estratégias argumentativas da eficiência ecoenergética e da qualidade de vida. Assim, a noção de cidade compacta reunia, da perspectiva de documentos da Comissão das Comunidades Europeias, os atributos de alta densidade e de uso misto, tendendo a possuir uma maior eficiência energética ao reduzir as distâncias dos trajetos, maximizar a oferta de transporte público e prover os residentes de uma melhor qualidade de vida.

A metáfora da cidade compacta teve, como configuração formal mais aceita, o modelo policêntrico em rede, com diversificação de funçôes dos subcentros bem servidos de transportes públicos (CAMAGNI; GIBELLI, 1997). Contudo, sua capacidade de conjugar a eficiência no uso dos recursos ambientais com a qualidade da vida urbana não foi aceita de forma consensual. Para Jim (2004), o modelo de cidade compacta incorre em obstáculos físicos (dados os limites de expansão do sítio urbano), institucionais e legais, restringindo a quantidade e qualidade da preservação da vegetação no ambiente urbano. Ademais, a recente tendência em adotar a política de cidade compacta em alguns países desenvolvidos também exige uma abordagem diferente, capaz de incluir a preservação e a ampliação das áreas verdes. Como as estratégias da política econômica nacional podem convergir, cidades de ambos os mundos (desenvolvido e em desenvolvimento) necessitam da troca de conhecimentos obtidos de experiências exitosas (JIM, 2004).

Há a crença de que a eficácia energética e a melhoria na qualidade de vida são atributos de cidades pouco densas e descentralizadas, uma vez que estas recorrem a fontes locais de energia e de produção de alimentos em solos rurais disponíveis. Nesses modelos de cidades, emprega-se o argumento de que a forma sustentável deve mesclar, ainda que em escalas distintas, zonas de trabalho, moradia e lazer, reduzindo distâncias e "pedestrizando" o espaço urbano, de modo a frear a mobilidade de energia, pessoas e bens. A eficiência ecoenergética e as condiçóes de vida da população resultariam, no âmbito desse discurso, da emergência de formas urbanas capazes de expressar o desejo crescente de cidades autossuficientes (ACSELRAD, 1999). Nessa hipótese prevalece, explícita e implicitamente, a expectativa de que a contração das áreas urbanas, por meio de sistemas de construçóes, favoreça o aumento de espaços livres. A verticalização, segundo tal discurso, permitiria uma maior concentração demográfica, favorecendo, assim, a criação/preservação de espaços abertos de uso público, livres do efeito da verticalização e da alta densidade demográfica.

O debate sobre a relação entre crescimento urbano, verticalização e qualidade de vida urbana não é ignorado pela mídia. Os argumentos que nela aparecem são centrados na oferta de áreas verdes e de uso público e no uso planejado do solo, sobretudo nos problemas ambientais relacionados à exposição da população a riscos, comumente ligados a fatores geotécnicos de inundações/enchentes. Um bom exemplo
$8 \mathrm{~A}$ ideia das cidades compactas é uma contribuição europeia, proposta para reduzir os custos de construção de infraestruturas, propiciar uma circulação mais eficiente e menos dispendiosa e para reduzir a necessidade de expansão urbana sobre novas áreas naturais (SILVEIRA; SILVEIRA, 2014).

9 Rogers e Gumuchdjian (1997) defendem um conceito de "cidade compacta" caracterizado por: evitar a ex pansão sobre as áreas rurais e de preservação ambiental; aumentar o desempenho da energia; reduzir o nível de poluição e o consumo de recursos; oferecer vantagens de se morar ao lado do outro pela redescoberta dos benefícios da proximidade, sem o risco à saúde, fato típico das cidades densas do século XIX. Para esses autores, a cidade compacta é essencialmente sustentável e promove a equidade, abrigando atividades diversas e, ao mesmo tempo, sobrepostas. É uma cidade livre que favorece os contatos pessoais em espaços coletivos - uma cidade bela e conectada com a arte e, ainda, possível de ser reconstruída. 
10 Para Glaeser (2011), se são observados os países mais urbanizados do mundo, verifica-se que não há países pobres. Disso surge a ideia de que a cidade representa, independentemente do modo de apropriação do espaço, uma forma de panaceia de desenvolvimento. 11 Tratalos et al. (2007), a partir da investigação de como a forma urbana afeta o desempenho ecológico do ambiente urbano, por meio de uma avaliação das relações entre forma urbana e medidas de qualidade ambiental e do potencial de biodiversidade em cinco cidades do Reino Unido, sugerem que não são evidentes os impactos sobre o desempenho ecológico e ambiental das zonas associadas à elevada densidade de desenvolvimento urbano. Os desafios para medir a densidade urbana indicam que são necessários vários indicadores para uma boa compreensão de como o fenômeno está relacionada ao desempenho ecológico. O uso da densidade domiciliar, por exemplo, como uma única medida de densificação pode subestimar a densidade urbana no centro da cidade, devido à proporção relativamente pequena de edifícios que são residenciais (TRATALOS et al., 2007). Utilizando como base metodológica de avaliação a ferramenta denominada Qualidade do Espaço Residencial (QER), adaptada à realidade do bairro Tambaú, em João Pessoa (PB), Silveira e Silveira (2014) concluem que a verticalização pode interferir na área onde esse processo se insere, por exemplo, por meio do incremento do tráfego de veículos ou, como demonstram Scussel e Sattler (2010), pelo aumento da poluição do ar, sonora e visual - responsáveis por alterar, negativamente, os níveis dos indicadores de qualidade do ambiente urbano. de exposição pública desse debate ocorreu na edição de dezembro de 2011 da revista National Geographic do Brasil, cuja matéria de capa trazia a ideia de que a solução para a crise ambiental proveniente da escassez dos recursos naturais e das mudanças climáticas poderia ser encontrada na concentração da população em cidades ${ }^{10}$. Tratase de uma questão que requer, além de retórica, uma análise apurada, fundada em evidências empíricas e em reflexôes menos tendenciosas ${ }^{11}$. A aposta em uma relação direta e automática entre concentração populacional e preservação ambiental, mais que uma simplificação analítica, pode ser a base de um discurso, eminentemente ideológico, que justifica a apropriação do espaço urbano por meio de um alto grau de adensamento construtivo, o que favorece a atuação especulativa de agentes do mercado imobiliário.

\section{MATERIAIS E MÉTODOS}

As bases digitais utilizadas neste trabalho - em formato vetorial (planta cadastral de Belo Horizonte, malha digital pontual altimétrica e setores censitários) e matricial (imagem de satélite de alta resolução) - permitiram a elaboração de dois conjuntos de indicadores, quais sejam: verticalização e impermeabilização do solo, como mostra a Figura 1. A estimativa de verticalização foi obtida do tratamento dos dados altimétricos extraídos por sensores remotos ativos (imageamento a laser). Utilizando técnicas de geoprocessamento, por meio das ferramentas de Intersect e Dissolve, disponíveis no aplicativo ArcMap/Arcgis ${ }^{\circledR}$, os valores de altitudes, dispostos em uma matriz de pontos (1x1 metro), foram incorporados aos polígonos das edificaçôes de Belo Horizonte $^{12}$. Em seguida, para cada um dos vetores que representavam as edificaçōes de uso particular, foi indexado um atributo relativo à estimativa de altura, derivado da média aritmética simples da matriz de pontos. A Figura 2 representa os valores de verticalização (altura média em metros) para os setores censitários de Belo Horizonte, conforme o recorte definido no Censo Demográfico de 2000 $0^{13}$. Em geral, os resultados preliminares possibilitaram observar, como esperado, que os maiores níveis de verticalização correspondem às áreas centrais e pericentrais, ainda que outras áreas também se destaquem no município. São espaços que, do ponto de vista legal, possuem legislação mais permissiva e que apresentam maiores níveis de Coeficiente de Aproveitamento (CAs), em funçáo de um zoneamento urbano com menor restriçáo à atuação de grandes corporações do mercado imobiliário ${ }^{14}$.

O indicador de impermeabilidade foi derivado, em uma primeira etapa, da classificação do mosaico de cenas referentes ao ano 2000, oriundo das imagens orbitais do sistema RapidEye, com resolução espacial de 5 metros $^{15}$. As áreas impermeáveis foram identificadas por uma classificação supervisionada por pixel, usando o método da Máxima Verossimilhança (ferramenta disponível no Spring 5.2.1 ${ }^{\circ}$ ). Em um segundo momento, com base em "máscaras vetoriais", foram extraídas todas as células da matriz que não era "ocupável" do ponto de vista legal, como as Zonas de Preservação Ambiental (ZPAMs), algumas zonas de grandes equipamentos urbanos (ZEs), as áreas verdes de uso público e as Áreas de Preservação Permanente (APPs), bem como aquelas com restriçóes de uso particular, como as vias (ruas, avenidas, travessas etc.), os parques, as praças, os corpos hídricos etc. As categorias da classificação que se referem às áreas edificadas/impermeabilizadas de uso particular foram exportadas 
em formato vetorial, o que permitiu calcular a proporção de impermeáveis em cada setor censitário (Figura 2). Diferente da distribuição espacial observada para a altura das edificaçôes, as áreas impermeáveis são menos concentradas, com uma frequência de valores elevados fora da área central e em setores com amplas áreas menos verticalizadas.

Figura 1: Resumo metodológico

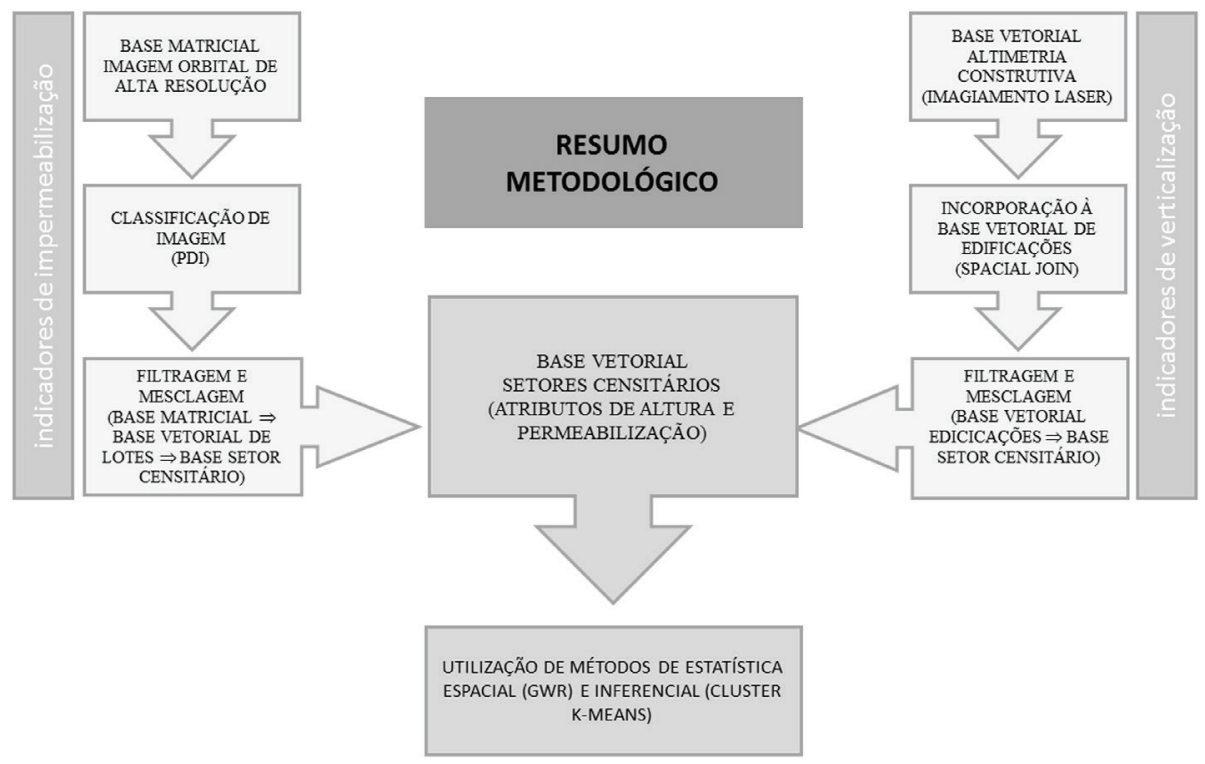

Fonte: Elaborado pelos autores.

As bases digitais obtidas das técnicas descritas, incluindo as estimativas de verticalização e impermeabilização, permitiram, ao executar ferramentas do software SPSS ${ }^{\oplus}$ a aplicação de métodos de estatística espacial e multivariada. A partir dos atributos altura média das edificaçóes e percentual de área impermeável, foi utilizado o modelo Geographically Weighted Regression (GWR) ${ }^{16}$, a fim de avaliar a prediçáo dos níveis de impermeabilização do solo (variável dependente), com base no parâmetro de verticalização, estimado pela altura média das edificaçóes (variável independente/explicativa). Além dos índices de regressão local $\left(R^{2}\right)$ estimados para cada setor censitário, foram identificados os padrōes e a distribuição espacial dos resíduos, que representam os casos de maior e menor explicação do modelo. Complementarmente, recorreu-se ao método de classificação $k$-means ${ }^{17}$, com o propósito de definir os agrupamentos, identificando os clusters compostos pelos setores censitários por combinação de diferentes níveis de verticalização e impermeabilização do solo ${ }^{18}$.
12 Os dados da altimetria construtiva, derivados das bases topográficas cedidas pela $\mathrm{PBH} /$ Prodabel, foram corrigidos em função de um Modelo Digital de Terreno (MDT).

13 Foram utilizados os dados do Censo Demográfico de 2000 pelo fato de este ser uma base mais compatível temporalmente com o levantamento orbital do sistema RapidEye disponibilizado pela $\mathrm{PBH}$, que também se refere ao ano 2000.

14 É bom destacar, contudo, que parte das áreas centrais é de ocupação antiga, o que extrapola o poder de explicação do caráter menos restritivo da legislação.

15 As cenas de imagem do RapidEye passaram por um pré-processamento, que consistiu em: registro; correção geométrica e radiométrica; mosaicagem e filtragem (filtro de mediana); e realce, utilizando o aplicativo Spring 5.2.1 ${ }^{\circledR}$.

16 Trata-se de uma ferramenta desenvolvida com o propósito de analisar fenômenos que sofrem variação na área estudada, derivada da heterogeneidade espacial. O modelo GWR tem como base o ajustamento de um modelo de regressão local para cada elemento no conjunto de dados, ponderando as observações em razão da distância a esse elemento. Pressupõe-se que pontos mais próximos ao ponto de estudo têm maiores influências nos parâmetros da regressão que os mais distanciados (CARVALHO et al., 2006). O método usado para definir a largura de banda ou vizinhos foi o AICC (Akaike Information Criterion). Esta é uma medida de desempenho, e ela é útil para comparar diferentes modelos de regressão. Nela, leva-se em conta a complexidade do modelo, o que possibilita um melhor ajustamento dos dados observados. AICC não é uma medida absoluta de bondade de ajuste, mas é útil para comparar modelos com diferentes variáveis explicativas, aplicados à mesma variável dependente. 
Figura 2: Percentual de impermeabilização do solo e altura média das edificações particulares nos setores censitários de Belo Horizonte/MG, 2000

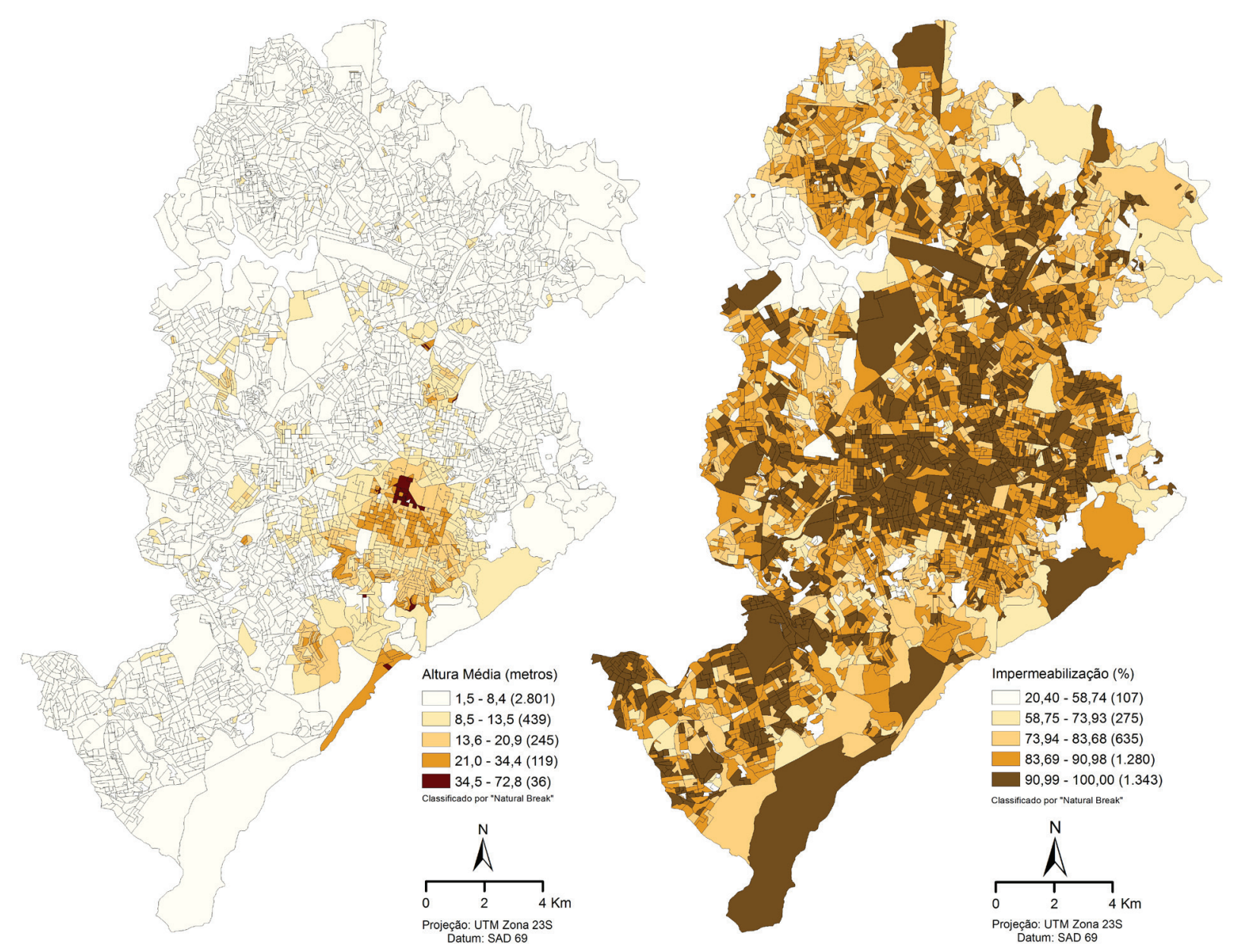

17 Considerado como não hierárquico, o k-means é um método de classificação que leva em conta a distância de cada elemento amostral, cujo centroide corresponde ao ponto mais próximo do vetor de valores observados para o respectivo elemento (MINGOTI, 2005).

180 agrupamento inicial e o número de classes $(K=9)$ foram definidos utilizando inicialmente o método TwoStep Cluster. Uma grande vantagem desse método é a possibilidade automática de encontrar, caso seja desconhecido, o chamado "valor ótimo" de agrupamentos, obtido das informações estatísticas fornecidas pelo Critério de Informação Bayesiano (BIC ou CIB).
Fonte: Cadastro Municipal PBH/Prodabel, Censo Demográfico de 2000 e Mosaico de Cenas RapidEye 2000 (resolução: 5m).

\section{EVIDÊNCIAS NO CASO DE BELO HORIZONTE: ANÁlise E DISCUSSÃO DOS RESULTADOS}

De modo geral, como representado na Figura 3, os resultados sugerem que não há uma associação direta entre a altura média das edificações e a proporção de áreas impermeáveis nos setores censitários de Belo Horizonte. O valor de $R^{2}$ global ajustado, definida a altura das edificaçóes como variável explicativa, foi de 0,2. Os escores de $R^{2}$ local também foram baixos e náo ultrapassaram o valor de 0,2 , o que sugere o baixo poder explicativo do nível de verticalização sobre o percentual de áreas permeáveis em cada agrupamento dos setores censitários. Contudo, os escores de resíduo padronizado permitem identificar algumas particularidades na distribuição espacial. 
Figura 3: Verticalização e Impermeabilização do solo nos Setores Censitários de Belo Horizonte/MG, 2000 - Regressão Espacialmente Ponderada (GWR): R² e Resíduos Padronizados

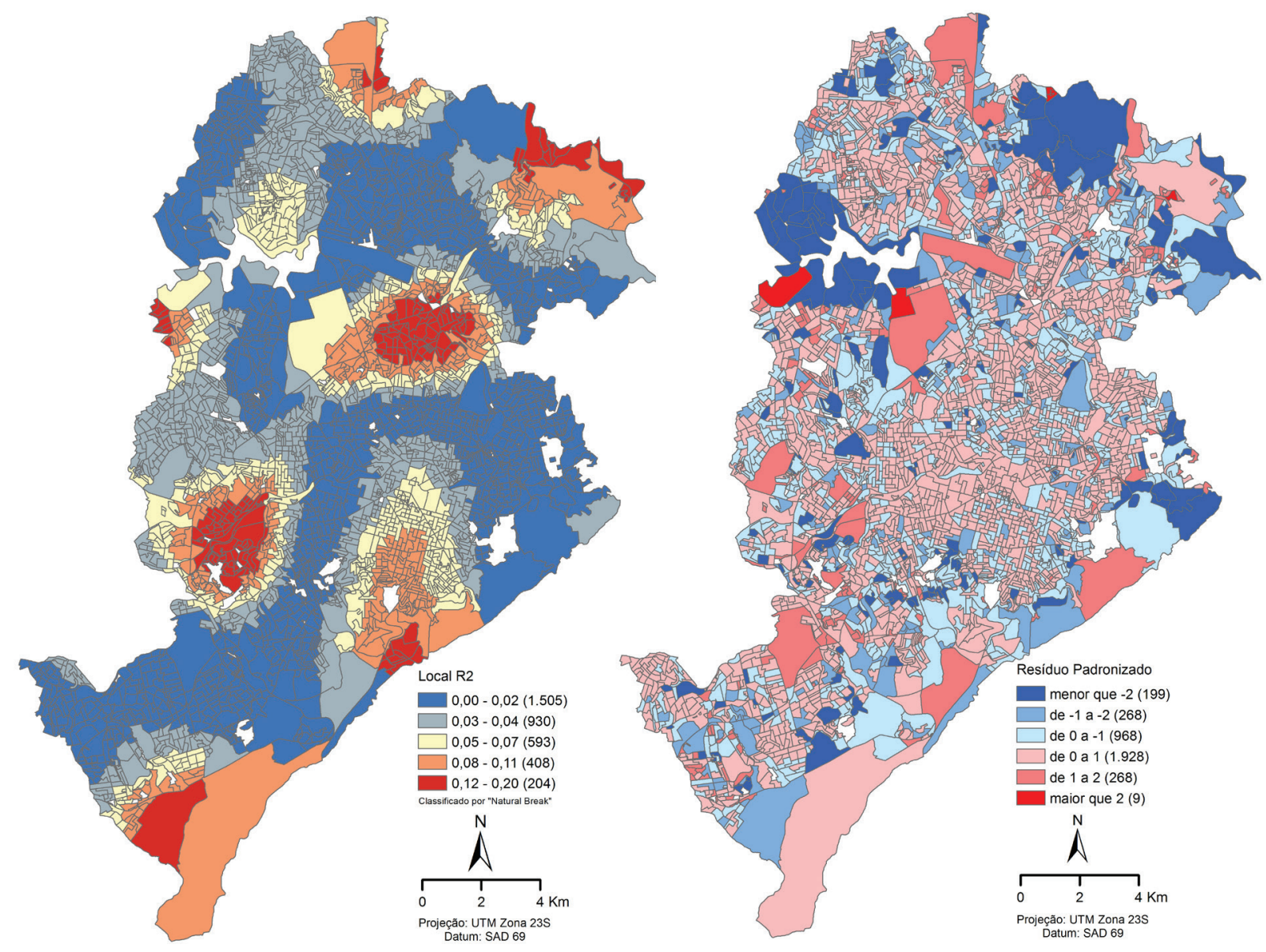

Fonte: Cadastro Municipal PBH/Prodabel, Censo Demográfico de 2000 e Cenas RapidEye 2000.

Enquanto os setores censitários com valores de impermeabilização que se ajustam melhor aos parâmetros estabelecidos pelo modelo se distribuem de modo mais disperso, sobretudo aqueles com desvios positivos em relação ao valor predito, os que mais destoam da reta de regressão apresentam uma relativa concentração espacial. Como observado na Figura 3, destacam-se nesse grupo 199 setores, cujos valores de desvio padrão são inferiores a 2, localizados próximos da orla da Lagoa da Pampulha e também em partes das regiôes Norte e Leste de Belo Horizonte. Em tais casos, os valores de impermeabilização são menores que o esperado, dadas as médias de altura das edificaçôes. Eles compóem, em sua maioria, loteamentos de classe alta e média alta, cujas áreas são maiores e correspondem às zonas com os Coeficientes de Aproveitamento (CAs) mais baixos, o que permite e induz a manutenção de maiores áreas não edificadas.

Além do baixo poder explicativo do modelo de regressão utilizado, os resultados da análise de cluster também não confirmam uma relação direta entre a verticalização e a proporção de áreas impermeáveis. Há, contudo, casos que caracterizam a relação

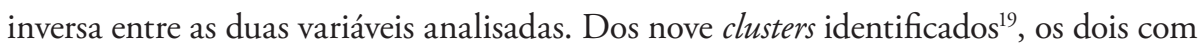
maiores níveis de altura das edificaçóes (clusters 8 e 9), cujos valores da mediana de

19 Os parâmetros obtidos do teste de Analise de Variância (ANOVA), cujos níveis de significância foram superiores a $95 \%$ em ambos os casos, indicam valores críticos $(F)$ que permitem identificar diferenças entre as médias dos clusters para as duas variáveis utilizadas (altura das edificações e percentual de impermeabilização). 
altura são superiores a 20 metros, correspondem àqueles com maiores níveis de impermeabilização do solo. Os valores do centroide desses agrupamentos correspondem a, respectivamente, $93,28 \%$ e $91,77 \%$ de área impermeável. Esses mesmos clusters (8 e 9), que compreendem 38 e 142 setores censitários, nessa ordem, localizam-se predominantemente na porção central de Belo Horizonte, em especial no chamado Hipercentro (Figura 4). Por outro lado, o cluster 7, que envolve 107 setores censitários com menor nível de impermeabilidade, concentra-se na regional Pampulha, notadamente às margens da lagoa. Nesse caso, os valores medianos de impermeabilização são os mais baixos. No entanto, existem vários setores desse agrupamento localizados em diversas Regionais Administrativas, particularmente em Venda Nova, Norte, Nordeste e Leste.

Figura 4: Verticalização e Impermeabilização do solo (Box-Plot) nos Setores Censitários de Belo Horizonte/MG, 2000, conforme classificação $k$-means

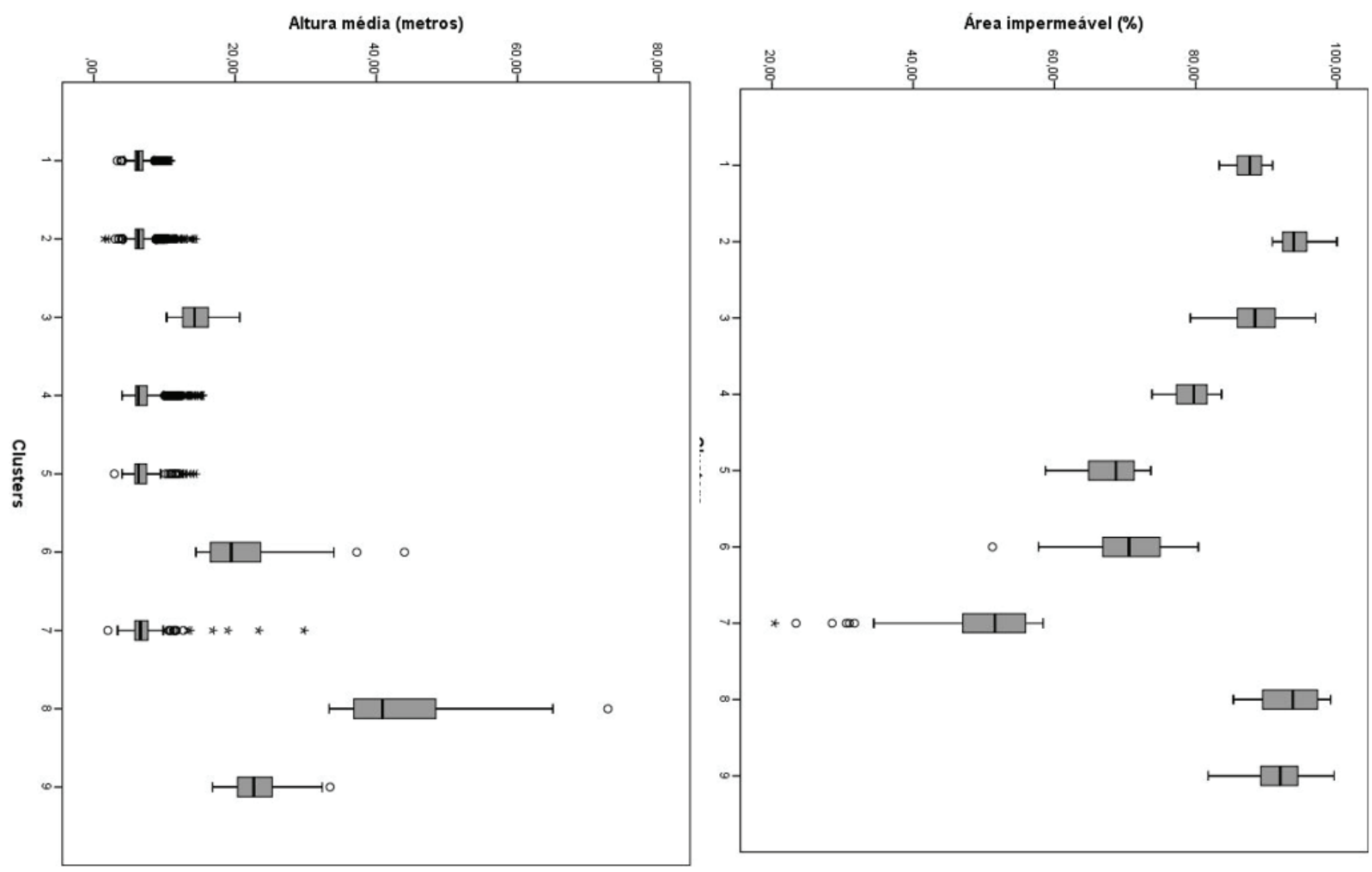

Fonte: Cadastro Municipal PBH/Prodabel, Censo Demográfico de 2000 e Cenas RapidEye 2000. 
Figura 5: Clusters de maior verticalização (k-means) nos Setores Censitários de Belo Horizonte/MG, 2000 (agrupamentos selecionados)

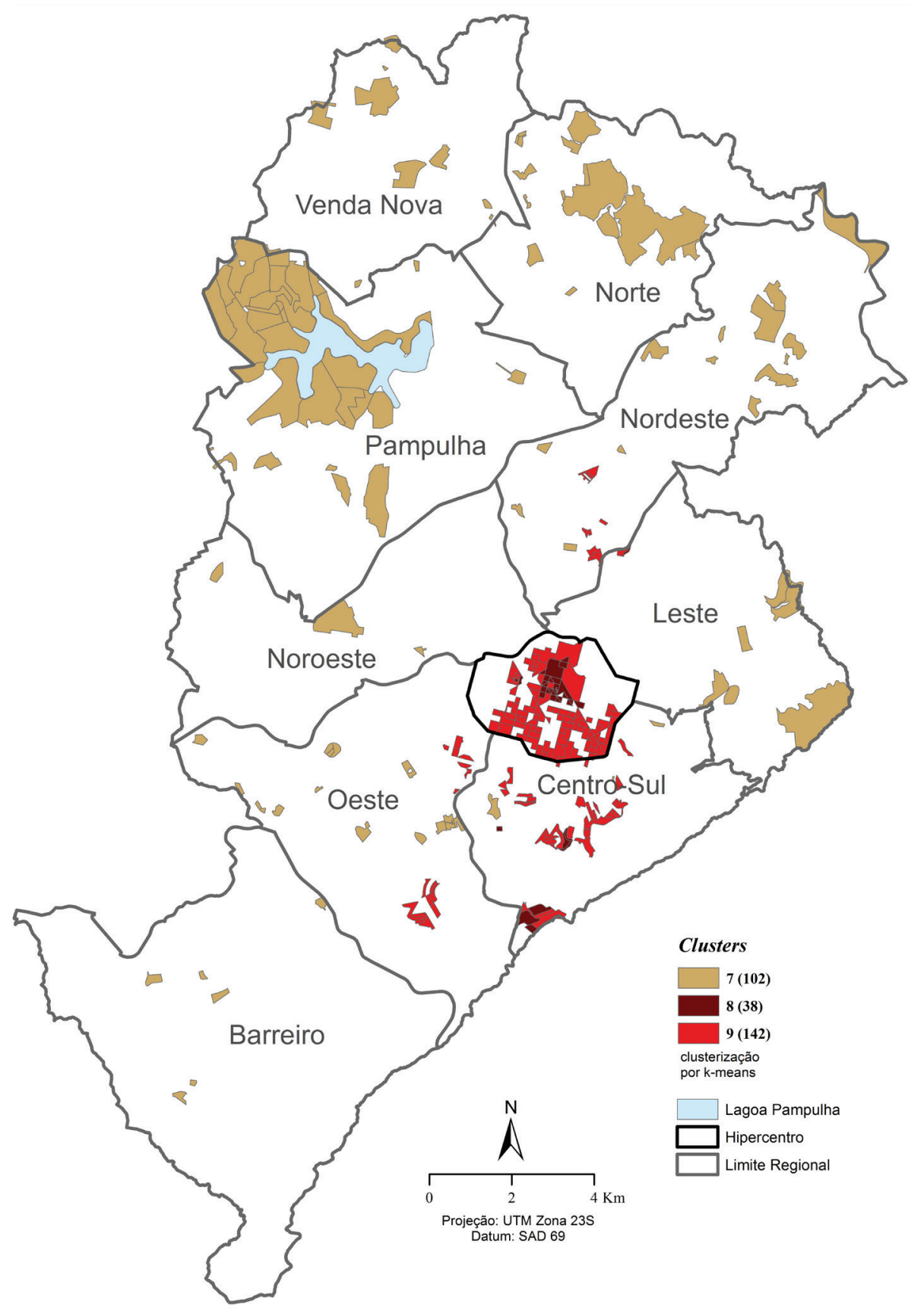

Fonte: Cadastro Municipal PBH/Prodabel, Censo Demográfico de 2000 e Cenas RapidEye 2000. 


\section{CONSIDERAÇÕES FINAIS}

Se, por um lado, a premissa de que a cidade compacta poderia reduzir os impactos ambientais derivados do crescimento acelerado do espaço urbano, notadamente aqueles decorrentes da perda de áreas permeáveis, possa parecer razoável no plano teórico, por outro, as evidencias empíricas trazidas neste paper revelam que os setores censitários de Belo Horizonte com maiores níveis de verticalização não correspondem àqueles com menor grau de impermeabilização do solo. Consideradas apenas essas variáveis, no recorte temporal e espacial analisado, os resultados demostram uma aleatoriedade estatística quando se observa a correlação espacial entre a verticalização e a existência de áreas permeáveis no espaço urbano da capital mineira. Os baixos valores de $\mathrm{R}^{2}$ confirmam o baixo poder de determinação da altura média das edificações sobre a variável.

Em Belo Horizonte, assim como em outros municípios brasileiros, a ocupação inadequada, não planejada ou mal planejada do espaço e a não observância da lei de uso e ocupação do solo vêm agravando uma série de problemas ambientais que afeta principalmente a população de baixa renda, a qual ocupa as chamadas áreas de riscos. O processo de verticalização, ainda que tenha a vantagem de concentrar a população em uma área menor, pode acentuar os níveis de degradação do espaço urbano, aumentando potencialmente os riscos ambientais de um adensamento populacional. Ademais, quando associado ao crescimento da impermeabilização do solo e à retirada da cobertura vegetal, esse processo pode contribuir para o desequilíbrio ambiental local, provocando, por exemplo, alteraçôes no microclima, diminuição da área de infiltração da água de chuva e elevação do escoamento pluvial, o que favorece o processo de enchentes e enxurradas. Os resultados sinteticamente apresentados, embora sejam limitados em suas escalas temporal e espacial, reforçam a necessidade de um maior investimento em análises mais detalhadas de problemas ambientais urbanos bastante discutidos no meio acadêmico e no cenário político internacional.

No Brasil, historicamente, o poder público não tem cumprido seu papel de mediador na ordenação do crescimento urbano e na definição de políticas eficazes, capazes de adequar o uso e a ocupação do solo às necessidades da população. $\mathrm{O}$ acentuado

Carlos Lobo: carlosfflobo@gmail.com.

Diego Ferreira Fonseca: diegof@oi.com.br.

Ricardo Alexandrino Garcia: alexandrinogarcia@gmail. com.

Artigo recebido em 19 de junho de 2015 e aprovado para publicação em 2 de dezembro de 2015. processo de verticalização, como alertam Silveira e Silveira (2014), tem confrontado combinaçôes e conflitos urbanos entre os atores que produzem e reproduzem o espaço intraurbano. Ele é resultado direto e indireto de açôes, projetos e também do jogo de interesses de atores que interagem no espaço da cidade. Em geral, a gestão e o planejamento urbano nas principais cidades brasileiras têm sido pouco efetivos em garantir a função social da terra, prevista na Constituição de 1988 e no Estatuto da Cidade, publicado em 2001, que inclui a dimensão ambiental. Tal ineficiência favorece a redução das áreas verdes e permeáveis do espaço urbano. Náo raro, isso tem elevado os custos para mitigar os efeitos ambientais negativos e, claro, onerado os cofres públicos. 


\section{REFERÊNCIAS BIBLIOGRÁFICAS}

ACSELRAD, H. Discursos da sustentabilidade urbana. Revista Brasileira de Estudos Urbanos e Regionais, n. 1, p. 79-90, maio 1999.

CAMAGNI, R. ; GIBELLI, M. C. Développement Urbain Durable-Quatre Métropoles Européennes. Paris: DATAR-L'Aube, 1997.

CARVALHO, L. E. et al. Regressão Linear Geograficamente Ponderada em ambiente SIG. Transportes, v. XIV, n. 2, p. 18-26, 2006.

CAVALHEIRO, F.; DEL PICCHIA, P. C. D. Áreas verdes: conceitos, objetivos e diretrizes para o planejamento. In: CONGRESSO BRASILEIRO SOBRE ARBORIZAÇÃO URBANA, 1., 1992, Vitória; ENCONTRO NACIONAL SOBRE ARBORIZAÇÃO URBANA, 4., 1992, Vitória. Anais do $1^{\circ}$ Congresso Brasileiro Sobre Arborização Urbana e do $4^{\circ}$ Encontro Nacional Sobre Arborização Urbana. Vitória: SBAU, 1992, p. 29-38.

CONGRESSO INTERNACIONAL DE ARQUITETURA MODERNA - CIAM. Carta de Atenas. Atenas: CIAM, 1933.

FERREIRA, N. S. M. A (des)verticalização de São Paulo. 1987. Dissertação (Mestrado em Arquitetura e Urbanismo) - Faculdade de Arquitetura e Urbanismo, Universidade de São Paulo, São Paulo, 1987.

FUNDAÇÃO JOÃO PINHEIRO. A questão ambiental em Minas Gerais: discurso e política. Belo Horizonte: Fundação João Pinheiro. Centro de Estudos Históricos e Culturais, 1996.

GLAESER, E. Triumph of the city: how our greatest invention makes us richer, smarter, greener, healthier, and happier. Nova Iorque: Penguin press, 2011.

JIM, C. Y. Green-space preservation and allocation for sustainable greening of compact cities. Cities, v. 21, n. 4, p. 311-320, 2004.

LIMA, F. T. de A. Parametrização do conceito de cidade compacta: uma abordagem "pósmoderna" para centros urbanos contemporâneos sustentáveis. Oculum Ensaios, Campinas, v. 11, n. 2, p. 259-270, jul./dez. 2014.

MACEDO, S. S. São Paulo, Paisagem e habitação verticalizada - os espaços livres como elementos do desenho urbano. 1987. Tese (Doutorado em Arquitetura e Urbanismo) Faculdade de Arquitetura e Urbanismo, Universidade de São Paulo, São Paulo, 1987.

MACHADO, J. R. e MÉNDES, C. M. O processo de verticalização do centro de Maringá-PR, Brasil. Investigaciones Geográficas, n. 52, p. 53-71, 2003.

MENDES, C. M. A Verticalização, um dos reflexos do processo da metrópole em formação: Maringá-PR. Boletim de Geografia, Maringá, v. 10, n. 1, p. 51-60, 1992.

MINGOTI, S. A. Análise de dados através de métodos de estatística multivariada: uma abordagem aplicada. Belo Horizonte: Ed. UFMG, 2005.

NUCCI, J. C. Qualidade Ambiental e Adensamento Urbano. São Paulo: Humanitas; FFLCH -USP, 2001.

PINHEIRO, A. Enchente e inundação - enchente em Porto Velho. In: SANTOS, R. F. (Org.). Vulnerabilidade Ambiental. Brasília: Ministério do Meio Ambiente. Secretaria de Qualidade Ambiental, 2007. p. 96-106.

RAMIRES, J. C. L. O processo de verticalizaçâo das cidades brasileiras. Boletim de Geografia, Maringá, v. 16, n. 1, p. 97-106, 1998.

ROGERS, R.; GUMUCHDJIAN, P. Cidades para um pequeno planeta. Barcelona: Gustavo Gili. 1997.

SANTOS, L. E. N.; TAVARES, J. C. A produção do espaço urbano e o cotidiano: reflexôes para o município de São Luís, MA. Cadernos de Pesquisa, São Luís, v. 18, n. especial, p. 7-17, dez. 2011.

SCUSSEL, M. C. B.; SATTLER, M. A. Cidades em (Trans)Formação: impacto da vertica- 
lização e densificação na qualidade do espaço residencial. Ambiente Construido, Porto Alegre, v. 10, n. 3, p. 137-150, jul./set. 2010.

SILVA, G. P. Forma Urbana e Sustentabilidade: algumas notas sobre o modelo de cidade compacta. Prospectiva e Planeamento. Lisboa, v. 15, p. 101-126, 2008.

SILVEIRA, F. A.; SILVEIRA, J. A. R. da. Qualidade do espaço residencial: efeitos da verticalização no bairro de Tambaú, na cidade de João Pessoa (PB). URBE. Revista Brasileira de Gestão Urbana, v. 6, n. 3, p. 289-305, set./dez. 2014.

SOMEKH, N. A cidade vertical e o urbanismo modernizador. São Paulo: Edusp, 1997.

SOUZA. M. A. A. A identidade da metrópole: a verticalização de São Paulo. 1989. Tese (LivreDocência em Geografia) - Faculdade de Letras e Ciências Humanas, Universidade de São Paulo, São Paulo, 1989.

. A identidade da metrópole: a verticalização de São Paulo. São Paulo: Edusp, Brasil, 1994.

TRATALOS, J. et al. Urban form, biodiversity potential and ecosystem services. Landscape Urban Planning, n. 83, v. 4, p. 308-317, dez. 2007.

UNITED NATIONS. Department of Economic and Social Affair. Population Division. World Urbanization Prospects: The 2014 Revision, Highlights. New York: United Nations, 2014.

ZAHN, C. E. O processo de urbanização: características e evolução In: BRUNA, G. C. (Org.). Questôes de organização do espaço regional. São Paulo: Edusp, 1983

A B S T R A C T : In the last decades, the discussion about the shape, the land occupation density in the cities and the environmental quality of urban spaces gained wide repercussions in the political scenario and international media. However, the relationship between the vertical expansion and the soil sealing level has been subject of recurring debate and controversy in the academic literature. Despite the fact the positive influence of permeable areas in urban environment quality seems consensual especially regarding the atmospheric and water dynamics, it is necessary to produce more accurate and detailed information, which are useful to decision-making in politics and territorial planning, especially the one under government jurisdiction. This paper is based on geo-referenced data, spatial statistics and inferential techniques. Therefore, we aim to analyze the influence of the concentration of vertical constructions and their relation to soil sealing, taking as an example the city of Belo Horizonte/MG. In general, considering the results of the linear regression model, it was not observed significant levels of determination of soil sealing, given the height values of the constructions. It is noteworthy, however, that the identified clusters that showed a high level of verticalization correspond exactly to those with higher levels of sealing soil.

K E Y W O R D S : vertical; permeabilization of urban land; Belo Horizonte. 